\title{
The Augmented Solow Model and the African Growth Debate
}

\author{
Anke E. Hoeffler \\ CID Working Paper No. 36 \\ January 2000
}

(C) Copyright 2000 Anke E. Hoeffler and the President and Fellows of Harvard College

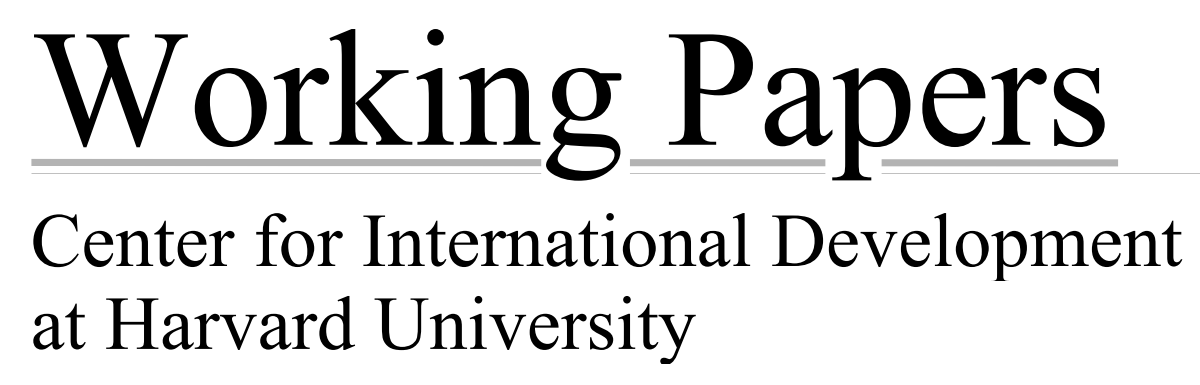




\title{
The Augmented Solow Model and the African Growth Debate*
}

Anke E. Hoeffler

\begin{abstract}
Using panel data the question whether Africa's growth performance can be accounted for is analyzed in the framework of the augmented Solow model. Our results indicate that this model can account for Africa's low growth performance, provided that we allow for unobserved country specific effects and the endogeneity of investment in estimating the parameters of the model.
\end{abstract}

Keywords: Growth, Panel Data Analysis, Sub-Saharan Africa

JEL Classification: C23, O40, O55

An earlier version of this paper was presented at the Workshop on "Explaining African Economic Growth Performance," held at Harvard University, March 26-27, 1999. The workshop was sponsored by the African Economic Research Consortium and the Weatherhead Center for International Affairs.

Anke Hoeffler's research interests are in the general area of growth and the economics of conflict. She holds a an economics degree from the University of Wurzburg, Germany and a Master of Science degree in Economics from Birkbeck College, University of London. She recently completed her

D.Phil. thesis "Econometric Studies of Growth, Convergence and Conflicts" at the University of Oxford. Prior to joining CSAE she was an economic consultant mainly working for the European Commission. Correspondence may be addressed to: Dr. Anke Hoeffler, Centre for the Study of African Economies (CSAE), 21 Winchester Road, Oxford OX2 6NA. Telephone: + (0)1865 274 551. Fax + (0)1865 274 558. E-mail:

anke.hoeffler@balliol.ox.ac.uk

*I would like to thank Stephen Bond for helpful discussion. 


\section{Introduction}

Within the empirical growth literature considerable attention has been paid to the slow growth performance of Sub-Saharan Africa. Among others Barro (1991, 1997), Levine and Renelt (1992) and Sala-i-Martin (1997a, 1997b) find that the coefficient on a dummy variable for African countries is negative and significant in a number of different specifications. The significance of the coefficient on the Africa dummy is interpreted as evidence that some regularities are missing from the model, i.e. that these growth models cannot fully account for Africa's low growth performance. The aim of this paper is to re-examine this standard result in the literature.

None of these studies have controlled for unobserved country specific effects or for the endogeneity of the regressors. We note that for a dynamic panel data model ordinary least squares (OLS) levels as well as within groups estimation are likely to suffer from biases due to endogeneity and unobserved country specific effects. We suggest a recently developed system generalized method of moments (GMM) estimator as our preferred estimation method for panel growth regressions, which we find confirmed by our results.

Using these preferred estimation results we suggest a 'two step' procedure to examine Africa's growth performance. We use the preferred coefficient estimates of the augmented Solow model obtained by system GMM estimation as the "step 
one' regression results and calculate the residuals. In the 'step two regression' we regress these residuals on the Africa dummy. We estimate this 'step two regression' by OLS. These 'step two regression' results describe whether the Africa dummy can account for some of the variation in countries' growth performance that is not explained by the augmented Solow model.

The paper is structured in the following way. Section 2 provides a brief discussion of the (augmented) Solow model. In Section 3 we discuss different estimation methods for growth regressions and present some results in Section 4. Section 5 concentrates on the examination of Africa's growth performance. The last section concludes.

\section{The Solow Model}

In the Solow model growth in output per worker depends on initial output per worker, $y(0)$, the initial level of technology, $A(0)$, the rate of technological progress, $g$, the savings rate, $s$, the growth rate of the workforce, $n$, the depreciation rate, $\delta$, the share of capital in output, $\alpha$, and the rate of convergence to the steady state, $\lambda .{ }^{1}$ Thus, the model predicts that a high saving rate will affect growth in output per worker positively, whereas high labour force growth (corrected by the rate of technological progress and the rate of depreciation) will have a negative effect on growth in output per worker. The basic model is 


$$
\begin{aligned}
\ln y(t)-\ln y(0)= & -\left(1-e^{-\lambda t}\right) \ln y(0)+\left(1-e^{-\lambda t}\right) \ln A(0)+g t \\
& +\left(1-e^{-\lambda t}\right) \frac{\alpha}{1-\alpha} \ln (s)-\left(1-e^{-\lambda t}\right) \frac{\alpha}{1-\alpha} \ln (n+g+\delta) .
\end{aligned}
$$

where $y(t)$ denotes the logarithm of output per worker in period $t$.

In the augmented version of the Solow model investment in human capital is an additional determinant of growth in output per worker

$$
\begin{aligned}
\ln y(t)-\ln y(0)= & -\left(1-e^{-\psi t}\right) \ln y(0)+\left(1-e^{-\psi t}\right) \ln A(0)+g t \\
& +\left(1-e^{-\psi t}\right) \frac{\alpha}{1-\alpha-\beta} \ln \left(s_{k}\right) \\
& +\left(1-e^{-\psi t}\right) \frac{\beta}{1-\alpha-\beta} \ln \left(s_{h}\right) \\
& -\left(1-e^{-\psi t}\right) \frac{\alpha+\beta}{1-\alpha-\beta} \ln (n+g+\delta)
\end{aligned}
$$

where $s_{k}$ and $s_{h}$ denote the proportion of output invested in physical and human capital, respectively and $\psi$ denotes the rate of convergence to the steady state.

We refer to equation (2.1) as the textbook Solow model and to equation (2.2) as the augmented Solow model. Equations (2.1) and (2.2) have for example been used as the framework for empirical analysis by Mankiw, Romer and Weil (1992) (henceforth MRW), Islam (1995) and Caselli, Esquivel and Lefort (1996) (henceforth CEL). We will follow these studies and base our empirical analysis on the same equations. 


\section{Methodology}

\subsection{Single Cross-Section Regressions}

Typically the empirics of long run economic growth have been analyzed in a cross section regression framework using average data for long periods of 25 or 30 years. MRW follow this approach, but other examples are the studies by Barro (1991), Levine and Renelt (1992) and Sala-i-Martin (1997a, 1997b). Their analysis is based on a regression of the following form

$$
g_{i}=\alpha+\beta y_{i}+\gamma x_{i}+u_{i}
$$

where $g_{i}$ denotes the growth rate of real GDP per worker averaged over a 25 or 30 year period, $y_{i}$ is the initial level of real GDP per worker, $u_{i}$ represents an error term and $i=1, \ldots, N$ denotes a country index. For empirical tests of the Solow model the regression includes two additional regressors, the investment rate and population growth. However, most empirical studies are based on more general models and include a range of other socio-economic variables. These variables are either initial values or average values over the time period. For the discussion of the econometric methodology it does not make any difference whether we think of the (augmented) Solow model or more general models and for expositional purposes we will concentrate here on a single regressor, $x_{i}$.

We will not use single cross-country regressions for the analysis of the Solow model for a number of reasons. First, reducing the time series to a single (average) 
observation means that not all available information is used. Second, it is very likely that single cross-section regressions suffer from omitted variable bias. Third, one or more of the regressors may be endogenous. Since single cross-section growth regressions potentially suffer from these problems we will instead use a dynamic panel data approach. Previous papers have used a dynamic panel data approach to address the omitted variable and/or endogeneity issues, most notably Islam (1995) and CEL. Within the dynamic panel data framework we concentrate on two estimators, the Arellano and Bond (1991) first differenced generalized method of moments (DIF-GMM) estimator and the Blundell and Bond (1998) system generalized method of moments (SYS-GMM) estimator. Both GMM estimators address the bias problems encountered in single cross-section regressions, because in a dynamic panel data model we will be able to account for unobserved country specific effects and allow for the endogeneity of one or more of the regressors.

Single cross-section growth regressions are likely to suffer from omitted variable bias, because for example they do not allow for any difference in the initial level of technology, $A(0)$, across countries. Thus, the error term, $u_{i}$, in the single crosscountry regression (3.1) is likely to contain unobserved country specific effects due to the difference in initial levels of technology, $A(0)$. These unobserved country specific effects are likely to be correlated with some of the observed regressors and in particular any permanent unobserved influences will necessarily be correlated 
with the initial GDP level. Thus, the OLS estimation of (3.1) is very likely to suffer from an omitted variable bias. However, accounting for unobserved country specific effects is not possible in the single cross-section model.

\subsection{Dynamic Panel Data Analysis}

An alternative approach is to exploit the time series data for each country and consider repeated observations for shorter periods, instead of averaging over the entire period of 25 or 30 years. This provides a panel data set for the study of economic growth. In a panel data model we can then explicitly account for permanent unobserved country specific effects, $\eta_{i}$. This provides a panel data model of the form

$$
g_{i, t}=\alpha+\beta y_{i, t-1}+\gamma x_{i t}+\eta_{i}+v_{i t}
$$

where $t$ denotes points in time $t=2, \ldots, T$. For example $g_{i t}$ may reflect the average growth rate over a series of five year periods, with $y_{i, t-1}$ being the level of income per worker at the beginning of each of these periods, and $x_{i t}$ being measured either at the beginning of each period, or as an average over each of the five year periods.

Since the relevant five year growth rate in (3.2) is the logarithmic difference in GDP per worker, we have the following dynamic panel data model

$$
y_{i t}-y_{i, t-1}=\alpha+\beta y_{i, t-1}+\gamma x_{i t}+\eta_{i}+v_{i t}
$$


or equivalently

$$
y_{i t}=\alpha+\beta^{*} y_{i, t-1}+\gamma x_{i t}+\eta_{i}+v_{i t}
$$

where $\beta^{*}=(\beta+1)$. It is important to note that the typical panel in the study of economic growth then has a small number of time series periods, i.e. $\mathrm{T}$ is small. Asymptotic results discussed below focus on the case where the number of countries $\mathrm{N}$ becomes large for fixed $\mathrm{T}$.

\subsubsection{OLS Levels Estimation and Within Groups Estimation}

As Hsiao (1986) shows, omitting unobserved time invariant country effects in a dynamic panel data model will cause OLS levels estimates to be biased and inconsistent. The lagged dependent variable, $y_{i, t-1}$, is positively correlated with the permanent effects, $\eta_{i}$. As a result the OLS levels estimate of the coefficient $\widehat{\beta}^{*}$ in the typical growth regression is likely to be biased upward. ${ }^{2}$

An alternative estimation technique which takes account of the unobserved country specific effects is the within groups estimator. For this method model (3.4) is transformed by subtracting out the time series means of each variable for each country. In this transformation process the country specific effects are eliminated, because the country specific effects $\eta_{i}$ are invariant over time. The transformed model is then estimated by OLS. ${ }^{3}$ However, as shown by Nickell (1981), using the within groups estimator will also provide biased and inconsistent estimates in a dynamic panel model with fixed T. In contrast to the OLS levels estimation, 
the within groups estimate of the coefficient $\beta^{*}$ is likely to be biased downward. Consequently, the estimate $\widehat{\beta^{*}}$ obtained from OLS levels can be regarded as an approximate upper bound on this coefficient, and the estimate obtained from within groups estimation can be regarded as an approximate lower bound.

\subsubsection{General Method of Moments Estimation}

In addition to these inconsistency problems one or more regressors in (3.4) may be correlated with $\eta_{i}$ and/or $v_{i t}$. Both problems can be addressed by using a first differenced GMM estimator (Hansen (1982)). In order to obtain a consistent estimate of $\beta^{*}$ as $N \longrightarrow \infty$ for fixed $\mathrm{T}$ we take first differences of (3.4) which eliminates the country specific effects $\eta_{i}{ }^{4}$

$$
\left(y_{i t}-y_{i, t-1}\right)=\beta^{*}\left(y_{i, t-1}-y_{i, t-2}\right)+\gamma\left(x_{i t}-x_{i, t-1}\right)+\left(v_{i t}-v_{i, t-1}\right)
$$

Since the differenced lagged dependent variable and the differenced error term are correlated OLS estimation of (3.5) will not produce a consistent estimate of $\beta^{*}$, even if the regressor, $x_{i, t}$, is strictly exogenous. Thus, valid instruments have to be found for $\Delta y_{i, t-1}=\left(y_{i, t-1}-y_{i, t-2}\right)$. Assuming that the errors are independent across countries and serially uncorrelated

$$
E\left(v_{i t} v_{i s}\right)=0 \text { for } s \neq t
$$

and that the initial conditions satisfy

$$
E\left(y_{i 1} v_{i t}\right)=0 \text { for } t \geq 2
$$


then values of $y_{i t}$ lagged two periods or more are valid instruments in the first differenced growth equation, since $y_{i t-2}$ and earlier values are generally correlated with $\Delta y_{i, t-1}$, but not with $\Delta v_{i t}$. According to these assumptions $y_{i, t-1}$ is predetermined with respect to $v_{i t}$, i.e. shocks to GDP in one time period are not correlated with initial GDP of this time period.

If the regressor $x_{i t}$ is strictly exogenous

$$
E\left(x_{i t} v_{i s}\right)=0 \text { for all } s, t
$$

then all the past, present and future values of $x_{i t}$ are valid instruments in each of the differenced equations, even if the $x_{i t}$ are correlated with $\eta_{i}$. However, there are a number of reasons to believe that some of the regressors in empirical growth models, e.g. investment, may not be strictly exogenous. There may be a feedback mechanism where past shocks to GDP are correlated with current investment. Maintaining the assumption that current shocks to GDP are uncorrelated with current investment, this means that

$$
E\left(x_{i t} v_{i s}\right) \neq 0 \text { for } s<t
$$

and

$$
E\left(x_{i t} v_{i s}\right)=0 \text { for } s \geq t
$$

Following Arellano and Bond (1991) we can then use values of the predetermined $x_{i t}$ lagged one period or more as valid instruments in the first differenced growth 
equation.

It is also straightforward to treat for example investment as an endogenous variable. This means that we are allowing for correlation between current investment and current shocks to GDP, as well as feedback from past shocks to GDP, i.e.

$$
E\left(x_{i t} v_{i s}\right) \neq 0 \text { for } s \leq t
$$

and

$$
E\left(x_{i t} v_{i s}\right)=0 \text { for } s>t \text { only }
$$

In this case, valid instruments in the differenced equations are values of the endogenous $x_{i t}$ lagged two periods or more.

However, as Blundell and Bond (1998) show, estimators relying on lagged levels as instruments for current differences are likely to perform poorly when the series are close to a random walk. In this case the available instruments are only weakly correlated with the endogenous variables, and the GMM estimator is likely to suffer from serious finite sample bias, as well as imprecision. Instead they suggest to estimate a system combining two sets of equations. One set of equations are the differenced equations (3.5)

$$
\left(y_{i t}-y_{i, t-1}\right)=\beta^{*}\left(y_{i, t-1}-y_{i, t-2}\right)+\gamma\left(x_{i t}-x_{i, t-1}\right)+\left(v_{i t}-v_{i, t-1}\right)
$$

for which we use suitably lagged levels of $y_{i t}$ and $x_{i t}$ as instruments, as discussed 
for the first differenced GMM estimation. The other set of equations in the system are the levels equations (3.4)

$$
y_{i t}=\alpha+\beta^{*} y_{i, t-1}+\gamma x_{i t}+\eta_{i}+v_{i t}
$$

Provided the $x_{i t}$ regressor satisfies

$$
E\left(\Delta x_{i t} \eta_{i}\right)=0
$$

and the initial conditions satisfy the restriction

$$
E\left(\Delta y_{i 2} \eta_{i}\right)=0
$$

we can use $\Delta y_{i, t-1}$ and $\Delta x_{i t}$ as instruments in the levels equations. ${ }^{5}$ Estimators of this type were proposed by Arellano and Bover (1995). Assumption (3.6) allows the level of $x_{i t}$ to be correlated with the unobserved country specific effects, $\eta_{i}$, but requires the changes in $x_{i t}$ to be uncorrelated with $\eta_{i}$. This is clearly weaker than requiring the levels of $x_{i t}$ to be uncorrelated with $\eta_{i}$. Given (3.6), assumption (3.7) will be satisfied provided the process (3.4) has been generating the $y_{i t}$ series for a sufficiently long time - this is a kind of stationarity restriction. Alternatively, Blundell and Bond (1999) show that sufficient conditions for (3.7) and (3.6) are for the series $x_{i t}$ and $y_{i t}$ to have time-invariant means.

As an empirical matter, the validity of these additional instruments can be tested using standard Sargan tests of overidentifying restrictions, or using Difference Sargan tests comparing first differenced GMM and system GMM results 
(cf. Arellano and Bond (1991)). Exploiting the additional restrictions (3.7) and (3.6) means that the system GMM estimator is more efficient than the differenced GMM estimator, provided these restrictions are valid. Blundell and Bond (1998) show that the efficiency gain can be dramatic when the series are close to being random walks, and that the differenced GMM estimator can also have large finite sample biases in these cases. In a model with no $x_{i t}$ variables, the differenced GMM estimate of the coefficient $\beta^{*}$ is found to be biased downward in small samples when the instruments are weak. More generally, Blundell and Bond (1999) show that if the instruments available are weak, the differenced GMM estimator will be biased towards the within groups estimator.

We now turn to a brief discussion of the unobserved country specific effects, $\eta_{i}$. One important question is whether we have to account for these unobserved country specific effects.

If the unobserved country specific effects are not significant, equation (3.4) becomes

$$
y_{i, t}=\alpha+\beta^{*} y_{i, t-1}+\gamma x_{i t}+v_{i t}
$$

and we could estimate (3.8) by instrumenting the endogenous regressors in the following way. Assuming as before that the errors are serially uncorrelated and that $x_{i t}$ are endogenous, values of $x_{i t}$ lagged one period or more are valid instru- 
ments for $x_{i t}$ in the levels equations. (Since $y_{i, t-1}$ are predetermined there is no need to instrument for them in the levels equations.) We refer to this estimation method as IV levels.

In Section 4 we compare the results estimating (3.8) by IV levels and estimating (3.4) by system GMM. (3.8) is a restricted version of (3.4), because according to model (3.8) all countries have the same intercept term, whereas (3.4) allows the intercept to vary across countries. Thus, the comparison of the IV levels and the system GMM results will allow us to examine whether significant country specific effects are present. As in the case of OLS levels, we would expect the IV levels estimate of $\beta^{*}$ to be biased upwards in the presence of significant country specific effects.

\subsubsection{The Treatment of Time Invariant Country Characteristics}

We now turn to a discussion of the inclusion of time invariant country characteristics, such as geographic location, in these growth regressions. If we include measured time invariant country characteristics, $w_{i}$, in our analysis, the growth equation (3.4) becomes

$$
y_{i t}=\alpha+\beta^{*} y_{i, t-1}+\gamma x_{i t}+\delta w_{i}+\eta_{i}+v_{i t}
$$

Since the measured country characteristics $w_{i}$ may be correlated with the unobserved country specific effects and/or the error term $v_{i t}$ we estimate the model 
in the following two step procedure. First, we estimate (3.9) without including the measured country specific characteristics, $w_{i}$

$$
y_{i t}=\alpha+\beta^{*} y_{i, t-1}+\gamma x_{i t}+\eta_{i}^{*}+v_{i t}
$$

where $\eta_{i}^{*}=\delta w_{i}+\eta_{i}{ }^{6}$ This allows us to obtain consistent estimates of the $\beta^{*}$ and $\gamma$ coefficients, whatever the correlation between $w_{i}$ and the error components. We then use these consistent estimates $\widehat{\beta^{*}}$ and $\widehat{\gamma}$ to estimate the residuals of equation (3.10). In the second step we regress these residuals on the measured country characteristics, $w_{i}$

$$
\left(y_{i t}-\widehat{\alpha}-\widehat{\beta^{*}} y_{i, t-1}-\widehat{\gamma} x_{i t}\right)=\delta w_{i}+\left(\eta_{i}+v_{i t}\right)
$$

The estimates $\widehat{\delta}$ describe which measured country characteristic can account for variations in the unobserved country specific effects. However, OLS levels estimates of (3.11) will generate consistent estimates of $\delta$ if and only if all $w_{i}$ characteristics are uncorrelated with $\eta_{i}$. Thus, in general this two step procedure will not solve the problem of biased estimates of $\widehat{\delta}$. The advantage of this two step procedure, compared with estimating (3.9) by system GMM under the assumption that the measured country characteristics, $w_{i}$, are uncorrelated with the unobserved country specific effects, $\eta_{i}$, is that the latter procedure would also give biased and inconsistent estimates of the $\beta^{*}$ and $\gamma$ coefficients if this strong assumption 
is not correct. Due to the presence of the unobserved country specific effects, we also expect the error term $\left(\eta_{i}+v_{i t}\right)$ of equation (3.11) to exhibit positive serial correlation.

\section{Testing the Augmented Solow model}

\subsection{Data and Sample}

One important question when testing the Solow model is whether to use per capita or per worker variables. According to the Solow model it seems more appropriate to use per worker GDP and the growth of the workforce, because the model is based on a production function and not every person contributes to production. We would expect the results of growth regressions to be sensitive to the very different dependency ratios across countries. In Sub-Saharan African countries for example the population growth rate has been higher than the growth of the workforce on average.

MRW use per worker variables, whereas Islam (1995) and CEL use per capita values. We have run all regressions in per worker as well as per capita terms. The results do not seem to be sensitive to the choice of per worker or per capita values. $^{7}$ This somewhat surprising result may be due to the data quality. Real GDP per capita and real GDP per worker data were obtained from the Penn World Table Mark 5.6 (PWT 5.6). Workforce in PWT 5.6 is defined as the working age population, i.e. the population aged 15-65. Censuses are taken about every 10 
years in most countries. Annual population data are obtained by interpolation and workforce data is calculated from these data. Workforce data are probably measured with considerable measurement error. Since the results seem to be robust to the choice of data we decided to concentrate on the per capita variables in order to make our results comparable to two other panel data studies by Islam (1995) and CEL.

In the Solow model per capita income growth depends on the initial level of per capita GDP, average savings and the average population growth rate (adjusted for the depreciation rate and the rate of technological progress). In the augmented version of the model a measure of schooling is added to the textbook version.

Real GDP per capita, $y_{i t}$, data was obtained from PWT 5.6. RGDPCH is the preferred measure of real per capita GDP, because it is adjusted for purchasing power parity and it is based on a chain index. Quinquennial real per capita GDP data is used, starting in 1960, 1965, ... and ending in 1990.

Following MRW, Islam (1995) and CEL we proxy the saving rate by the aggregate investment to GDP ratio. The data was obtained from PWT 5.6. The time series were averaged over 1960-64, 1965-69,.., 1985-89. ${ }^{8}$

Population data was obtained from a World Bank source, World Data, available on CD-ROM. It is superior to the population data reported by PWT 5.6, because there are discontinuities for a number of countries in the PWT 5.6 data 
series around 1970. Only for Taiwan, which is not available from the World Bank, was PWT 5.6 population data used. Average population growth rates were computed as the difference between the natural logarithms of total population at the end and beginning of each period and dividing this difference by the number of years. In this study the average population growth rates for $1960-64,1965-69, \ldots$ , 1985-89 were computed. ${ }^{9}$

Like Islam (1995), MRW and CEL, technological progress and the depreciation rate were assumed to be constant across countries and that they sum to 0.05 . The natural logarithm of the sum of population growth and 0.05 was calculated for $\ln (n+g+\delta)$

Instead of proxying human capital investment using school enrolment rates like MRW, we include a measure of the level of human capital in our regressions. ${ }^{10}$ Gemmell (1996) shows that proxying the level of human capital by using school enrolment rates is problematic, because it conflates the level and accumulation effects of human capital and leads to misinterpretations of the role of the labour force growth. To avoid these problems we proxy the level of human capital by the average years of schooling. Data collected by Barro and Lee (1996) provides the average years of total schooling for the population aged 15 and older. The data is provided quinquennially, starting in $1960,1965, \ldots$ and ending in 1990 . For this study schooling data at the beginning of each five year period was used. 
We do not include a proxy for the initial level of technology. In cross-country regressions it is implicitly assumed that both the level of initial technology and the rate of technological progress are common to all countries. Panel data studies, such as Islam (1995) and CEL, implicitly assume that the rate of technological progress is common to all countries, but allow for unobserved differences in the initial level of technology. Whilst this is a weaker restriction than that required for cross-country regressions to yield consistent parameter estimates, we are aware that it may still be unduly restrictive. Studies of the diffusion of new technology suggest that diffusion is likely to be costly, and take a considerable period of time. ${ }^{11}$ This is indeed an important motivation for allowing initial levels of technology to differ across countries. However, if the diffusion of new technology is not costless and instantaneous, we may want to go further and allow for different rates of technological progress in different countries. Nevertheless, in the absence of reliable data on rates of technological progress, we maintain the standard assumption of a common rate of technical change in this study. ${ }^{12}$

Data is available for 85 countries. ${ }^{13}$ However, data is not available for all countries for all of the six periods, thus, making the panel unbalanced. 


\subsection{Results}

\subsubsection{The Textbook Solow Model}

All reported results in this section are based on the textbook Solow model as shown by equation (2.1). The econometrics package used is DPD98 for Gauss (Arellano and Bond (1998)). All reported standard errors are corrected for heteroskedasticity. The parameter estimates reported from GMM estimation are one-step estimates. All regressions include time dummies which we found to be jointly significant in every regression. In order to conserve space the coefficients on the time dummies are not reported in the tables.

The left hand side variable is the change in the logarithm of real per capita GDP. First, an OLS levels regression was run. All variables are significant at the one percent level and have the expected sign. The negative coefficient on initial GDP as in most published growth regressions is interpreted as conditional convergence while investment is positive and population growth is negative as suggested by the Solow model. The implied speed of convergence, $\lambda$, is less than one percent per annum. The results are shown in the first column of Table 4.1.

[Table 4.1 about here]

Second a within groups estimator was used, the results are shown in the second column of Table 4.1. Comparing the estimated coefficients of the OLS levels 
regression and the within groups estimation, we see that the OLS levels regression provides a higher estimate for the coefficient on the lagged dependent variable than the within groups estimation. These estimates provide the approximate upper and lower bounds for the following regressions. Since the coefficient on the lagged dependent variable is lower than the one obtained by OLS levels, the implied speed of convergence based on the results of the within groups estimation is much higher than the estimate obtained from OLS levels, it is about five percent per annum.

Column 3 presents the results using the Arellano and Bond (1991) first differenced GMM estimator. We assume that initial GDP is predetermined and investment is endogenous. We assume that current population growth is exogenous, in the sense of being uncorrelated with shocks to GDP per capita in both the current and preceding five year periods, i.e.

$$
E\left((n+g+\delta)_{i t},\left(v_{i t}-v_{i, t-1}\right)\right)=0
$$

This allows the use of both current and lagged levels of population growth as instruments in the first differenced equations. ${ }^{14}$

All coefficients are statistically significant, although investment is only significant at the eight percent level. The main problem with these results is that the coefficient on the lagged dependent variable is very close to the within groups estimate. Simulation results reported in Blundell and Bond (1998) show that the first 
differenced GMM estimator may be subject to a large downward finite-sample bias in autoregressive models. ${ }^{15}$ It may be that the presence of explanatory variables other than the lagged dependent variable, and more particularly the inclusion of current or lagged values of these regressors in the instrument set, will improve the behaviour of the first differenced GMM estimator in particular applications. However, in our case the first differenced GMM estimate seems to be downward biased, because it is very close to the within groups estimate which is expected to be seriously biased downwards in a panel with six or fewer time periods (Nickell (1981)). Since the coefficient estimates obtained from first differenced GMM estimation are close to the ones obtained from within groups estimation the estimated speed of convergence is also similar to the one estimated by within groups. The Sargan test only accepts the validity of the instrumental variable set at the four percent level.

We suggest the use of the Blundell and Bond (1998) system GMM estimator as an alternative to the Arellano and Bond (1991) first differenced GMM estimator. Again treating investment as endogenous and population growth as exogenous in the sense described above, the system GMM results are presented in column 4 of Table 4.1. The coefficient on the lagged dependent variable falls between the 'upper and lower bounds', and the estimated speed of convergence is about two percent per annum. Since additional moment restrictions are used we expect the 
system GMM estimation to be more efficient; all standard errors apart from that for population growth are smaller than the standard errors obtained from the first differenced GMM estimation. All regressors are statistically significant at the one percent level. For the system GMM estimates the Sargan test does not reject the validity of the instruments, and the Difference Sargan test does not reject the validity of the additional instruments used compared to first differenced GMM.

Thus, system GMM is our preferred estimator for the Solow model for two reasons. The estimate of the coefficient on the lagged dependent variable is not obviously biased, i.e. it lies well above the within groups estimate and well below the OLS levels estimate, and the estimates of the coefficients are more precise than the ones obtained from first differenced GMM. The additional instruments used by the system GMM estimator appear to be both valid and highly informative in this context.

We suspect that the poor performance of the first differenced GMM estimator is due to the weakness of the instrument set used. Blundell and Bond (1998) argue that the first differenced GMM estimator is likely to perform poorly when the series are close to random walks. Lagged levels are then weak instruments for current differences. We consider strengthening the instrument set used by the basic first differenced GMM estimator by including a measure of human capital. The endogenous growth model as discussed by Romer (1990) provides a the- 
oretical basis for this choice of additional instruments. In his endogenous growth model human capital is a key input in the research sector which generates new designs and these in turn generate new investment opportunities. Based on this assumption we add lagged values of the average years of schooling to the basic instrumental variable set.

The results using this augmented instrumental variable set are shown in column 5. The Difference Sargan test does not reject the validity of the schooling variable as additional instruments. Notice that, compared to the basic first differenced GMM results, all three coefficients move towards our preferred system GMM estimates. Most importantly, the coefficient on the lagged dependent variable now lies well above the corresponding within groups estimate, and is not significantly different from the system GMM estimate. ${ }^{16}$ Investment, which was only significant at the eight percent level in the basic differenced GMM results, becomes significant at the one percent level when we include our schooling measure as an additional instrument. As we will show in the next section when testing the augmented Solow model, including the average years of schooling as a regressor turns out to be insignificant in most regressions. However, although schooling is insignificant as a regressor, including it in the instrument set appears to strengthen the instrument set significantly.

In column 6 we present the results from the IV levels estimation. The results 
are similar to OLS levels, and in particular the coefficient on initial income is significantly higher than the system GMM estimate. ${ }^{17}$ Both IV levels and OLS levels estimates of this coefficient would be biased upwards by unobserved country specific effects. Thus, we interpret this as evidence for the presence of significant unobserved country specific effects which requires estimation techniques which correctly account for these effects. According to the Sargan test, the validity of the instruments can only be accepted at the six percent level for the IV levels estimator.

Our preferred method of estimation, using the Blundell and Bond (1998) system estimator, only provides consistent estimates if there is no serial correlation in the shocks, $v_{i t}$. Thus, we test for second order serial correlation in the first differenced residuals. ${ }^{18}$ The hypothesis of no second order serial correlation in the first differenced residuals is not rejected for any of the GMM estimations.

However, for the OLS level estimation as well as for the IV levels estimation we find strong evidence of positive first order serial correlation in the levels residuals, and weaker evidence of higher order serial correlation. We interpret this as further evidence that the error term contains unobserved country specific effects, which causes the levels residuals to be serially correlated. 


\subsubsection{The Augmented Solow Model}

In this section we present the results obtained from testing the augmented Solow model as described in equation (2.2). The dependent variable is the change in the logarithm of real per capita GDP. It is regressed on the logarithm of initial GDP, the investment to GDP ratio, the population growth rate and the average years of schooling measured at the beginning of the period. Thus, we treat schooling as predetermined.

First, an OLS levels regression was run, the results are reported in column 1 of Table 4.2. As before for the textbook Solow model, the coefficients on all variables are statistically significant and of the expected sign. However, the schooling measure is only significant at the 10 percent level. The estimated speed of convergence, $\psi$, is about one percent.

[Table 4.2 about here]

Second, a within groups estimator was used, the results are shown in the second column of Table 4.2. Schooling is no longer significant. As before the OLS levels regression provides the approximate upper bound and the within groups estimation provides the approximate lower bound for the coefficient on the lagged dependent variable for the following regressions.

Column 3 presents the results using the Arellano and Bond (1991) first dif- 
ferenced GMM estimator, assuming that initial GDP and schooling are predetermined, that investment is endogenous and population growth is exogenous. Here the estimate of the coefficient on the lagged dependent variable falls between the OLS levels and within groups estimates, although it is not significantly different from the within groups estimate. Schooling is again not statistically significant.

Using the system GMM estimator the estimate of the coefficient of the lagged dependent variable falls between the 'upper and lower bounds'. The results are reported in column 4. Schooling is the only variable that is not significant. Again the coefficient estimates are generally more precise than the differenced GMM estimates, and neither the Sargan test nor the Difference Sargan test reject the validity of the additional instruments used.

In the last column of Table 4.2 we present the IV levels estimates. ${ }^{19}$ The coefficient on the lagged dependent variable is again close to the OLS levels estimate, and higher than the corresponding system GMM estimate. ${ }^{20}$ This is consistent with an upward bias, caused by not taking the unobserved country specific effects into account. Like in the OLS levels results we detect significant first order serial correlation in the levels residuals, which we interpret as further evidence for the presence of unobserved country specific effects. The Sargan test also rejects the validity of the levels IV instrument set at the four percent level.

The coefficient on initial GDP is significantly negative in all five regressions, 
confirming the so-called 'conditional convergence' hypothesis, a standard result in cross-country growth regressions. Investment is highly significant in all five regressions, even though investment is treated as endogenous in the differenced and system GMM results, as well as in the IV levels estimation. The coefficient on population growth is significantly negative in all regressions. Schooling is statistically significant only in the OLS levels regression and in the IV levels results; it is not statistically significant in any of the results that control for unobserved country specific effects. However, a number of studies have found that the partial correlation between schooling and growth is not robust. ${ }^{21}$ The Sargan test of overidentifying restrictions does not reject the instrument set used in the first differenced GMM and system GMM results. Moreover, the Difference Sargan test does not reject the use of the additional instruments in the system GMM estimation in comparison to the differenced GMM estimation. Again the system GMM estimator gives our preferred results. However, it is noticeable that the differences between the first differenced GMM results and the system GMM results are smaller here than they were for the textbook Solow model. Although schooling is not significant once we control for unobserved country specific effects, adding schooling to the instrument set used by the first differenced GMM estimator seems to strengthen the instrument set significantly. Indeed it was this observation that led us to consider using schooling as an additional instrument when estimating 
the textbook Solow model.

\section{Can the augmented Solow model account for Africa's low growth performance?}

A number of growth studies, for example Barro (1991, 1997), Levine and Renelt (1992) and Sala-i-Martin (1997a, 1997b), examine whether certain regions experienced significantly different growth rates from the rest of the world. These studies include regional dummies in their single cross-country growth regressions, which take a value of one if the country is located in the particular region and zero otherwise. In a Barro growth regression, a significant coefficient on a regional dummy means that this region's growth performance on average was significantly different from the rest of the World's during the sample period, after accounting for the effects of the included regressors. Thus, a significant coefficient on a regional dummy indicates that some regularities are missing from the model to explain the difference in regional growth, i.e. these regressions are not able to explain why these regions' growth rates have been different. Common findings are that countries in Sub-Saharan Africa and Latin America experienced on average lower growth rates, while East Asian countries experienced higher growth rates. However, in this paper we want to concentrate on the analysis of Africa's growth experience.

Africa's low growth performance and possible explanations have attracted con- 
siderable attention in the literature. ${ }^{22}$ There are two major studies in which the Africa dummy is not significant. In Easterly's and Levine's (1997, 1998) core growth regression the Africa dummy is negative and significant, however adding the average growth rate of the country's neighbours (weighted by their GDP) makes the Africa dummy insignificant. Furthermore, the study finds that neighbourhood spillovers magnify the effects from bad policies, such as high government deficits, repressed financial markets, distorted exchange rates and political instability. However, why these neighbourhood spillovers matter is not clear. The study suggests that since adaptation of technology to a local environment is risky, a foreign direct investor may find it easier to invest in a neighbouring country if the investment was successful in the first country. A neighbours' success may also have demonstration effects and reputation effects. However, trade does not appear to be the channel for spillover effects. Using trade weights Easterly and Levine found the spillover variable to be insignificant. Although the Africa dummy is insignificant in their study we remain sceptical as to how far the inclusion of a neighbourhood spillover effect really explains Africa's growth performance, because a neighbourhood variable is very similar to the concept of a regional dummy, i.e. for each African country, the neighbours will be other slow growing African countries.

Sachs and Warner (1997) pursue a different approach in their examination of 
the African growth performance. They specify essentially a neo-classical model and add their openness to international trade measure and a number of geographical variables, such as a landlocked dummy and a tropical climate dummy. The model is a single cross-country growth regression and the estimation method is OLS. An Africa dummy is added to the core model and found to be insignificant. Thus, Sachs and Warner suggest that poor policies, most importantly lack of openness to international trade, as well as geographical factors such as tropical climate and being landlocked are the key variables in explaining Africa's poor growth performance. However, we will show that once we allow for unobserved country specific effects in estimation, the Africa dummy is found to be insignificant even in a basic augmented Solow growth model.

Before turning to our regression results we present some descriptive statistics for our panel data set by region. As can be seen from Table 5.1 Sub-Saharan Africa (SSA) experienced comparatively low growth rates per annum (0.52 percent).

[Table 5.1 about here]

Turning to the explanatory variables we see that the average initial income per capita for Sub-Saharan African countries was very low, only about 37 percent of the average initial income per capita. Thus, according to the conditional convergence hypothesis African countries should have experienced higher than average growth rates, ceteris paribus. However, on average Sub-Saharan African countries 
invested less of their GDP (9.02 percent) than the average country (16.29 percent), they had higher population growth (2.21 percent) than the average country (1.66 percent) and much lower initial schooling (1.27 years) than the average country (3.47 years). These differences should account for some of Africa's low growth performance.

We now turn to our regression results. First, we include a dummy variable for African economies in the augmented Solow model. The dummy takes the value of one if the country is located in Sub-Saharan Africa, and zero otherwise. We first estimate this model by OLS levels, the results are presented in the first column of Table 5.2.

[Table 5.2 about here]

The coefficient on the Africa dummy is significant and negative. This confirms the commonly found result in the literature when unobserved country specific effects and endogeneity are not accounted for, i.e. the Solow growth model appears to be unable to account for the growth experience of African economies.

Note however that we find significant positive autocorrelation in the residuals from the OLS regression. This is consistent with the presence of unobserved country specific effects which are not accounted for in the OLS regression.

Since the OLS estimates suffer from fixed effects and endogeneity biases we now use our preferred 'two step estimation' procedure to estimate the coefficient on 
the Africa dummy. We use the consistent coefficient estimates from system GMM estimation of the augmented Solow model to calculate the residuals of this growth regression. For convenience we repeat the system GMM coefficient estimates in Table 4.2, column $2 .{ }^{23}$ Notice that the effects of investment and population growth are found to be substantially higher in these system GMM results. We then regress these residuals on the Africa dummy, the results are presented in column 3. We find that the coefficient on the Africa dummy is insignificant.

Thus, the Africa dummy is not required to account for the variations in growth rates once we control for the presence of unobserved country specific effects in estimating the model. This suggests that the augmented Solow model can account for the difference in the growth performance experienced by the African countries. Given our preferred coefficient estimates, the low investment ratios and high population growth rates of the African countries are sufficient to explain their slow growth of income per capita.

\section{Conclusion}

Knowledge of the likely direction of the bias in OLS as well as within groups estimation in dynamic panel data models with unobserved country specific effects and a small number of time periods was used to establish approximate upper and lower bounds for the estimated coefficient on the lagged dependent variable in growth 
regressions. Using first differenced GMM estimation we found that the estimated coefficient on the lagged dependent variable appeared to be biased downward. We suggest that the first differenced GMM estimator is likely to perform poorly when the series are persistent and the number of time series observations is small, because past levels of the series provide weak instruments for the variables in first differences. However, a system GMM estimator (using not only lagged levels of the series as instruments in the first differenced equation, but also lagged differences of the series as instruments in the levels equation) was shown to be the preferred method, since it produced more precise and more reasonable coefficient estimates than the estimates obtained from differenced GMM. The additional instruments used by the system GMM estimator were not rejected, and were found to be highly informative in these empirical growth models.

We then addressed the question whether the augmented Solow model can account for Africa's growth experience. The commonly found result in the literature, that basic growth models are unable to account for Africa's low growth performance, was only supported by our OLS levels estimation. However, when we account for unobserved country specific effects and endogeneity using our 'two step regression' procedure, we cannot confirm this result. In the 'first step' of our estimation procedure, we use the preferred system GMM coefficient estimates of the augmented Solow model in order to calculate the residuals. In the 'step 
two regression' we investigate whether the Africa dummy can account for some of the variation in these growth regression residuals. We find that the coefficient on the Africa dummy is insignificant. This suggests that the augmented Solow model can fully account for Sub-Saharan Africa's low growth performance provided we account for unobserved country specific effects and for the endogeneity of investment in estimation. 


\section{Appendix: Alternative Treatments of Investment and Population Growth in the Solow Growth Model}

In our preferred specification presented in Sections 3 and 4 we assumed that investment is endogenous and that population growth is exogenous. Here we want to examine these assumptions by comparing alternative specifications.

We first examine our treatment of investment. In all regressions in Table 7.1 we use system GMM and make the same assumptions about initial per capita GDP and population growth as before, but examine the effect of different assumptions about investment. We can treat investment as either exogenous ${ }^{24}$, predetermined or endogenous. One result is common to all regressions presented in this table, no matter which assumption we make about investment, the coefficient on investment is positive and significant at the one percent level. However, the different treatment of investment does change the coefficient on the lagged dependent variable and thus the estimated speed of convergence. If we assume investment to be either exogenous or predetermined the estimated speed of convergence is higher than the two percent estimated from the regression where we assume investment to be endogenous. In either of these alternative specifications, the coefficient on the lagged dependent variable again becomes insignificantly different from the (biased) within groups estimate.

[Table 7.1 about here] 
In this table we also investigate the effects using a smaller instrumental variable set. The power of the Sargan test is often low, in particular if the number of instruments used is large in a relatively small sample. For a valid set of instrumental variables we expect that a reduction of the number of instruments used would result in not rejecting the validity of the instrumental variable set at a higher probability level. In column 1 we assume investment to be exogenous, i.e. we assume that both current and previous five year period shocks to GDP per capita are uncorrelated with current investment. In this case we use all current and past levels of investment as instruments in the first differenced equations, and the current first difference of investment as an instrument in the levels equations. According to the Sargan test the validity of these instruments is not rejected. However, when we reduce the number of instruments by only using the current and first lagged levels of investment as instruments in the first differenced equations, ${ }^{25}$ in column 2 , the Sargan test only accepts the validity of the instrumental variable set at the six percent level. Note that the coefficient estimates remain nearly unchanged. Based on the restricted set of instruments, the Sargan test therefore does provide some evidence against the assumption that investment rates can be treated as exogenous. This is consistent with the differences in the estimated coefficients, particularly on the lagged dependent variable and investment, compared to our preferred specification in which investment rates 
are treated as endogenous.

We observe a similar effect when we assume investment to be predetermined. In this case we assume that current shocks to GDP per capita are uncorrelated with current investment, but that past shocks to GDP per capita may be correlated with current investment. This allows us to use levels of investment lagged one and more periods as instruments in the first differenced equations. The results for the full instrument set, using all available lags, are presented in column 3. Again the Sargan test does not reject the validity of this instrumental variable set. However, when we reduce the instrument set and only use levels of investment lagged once and twice as instruments in the first differenced equations, in column 4 , the Sargan test only accepts the validity of the instrumental variable set at the eight percent level.

In the last two columns we treat investment as endogenous (the results for the full instrument set in column 5 are the same as those in Table 4.1 column 4). When we reduce the instrumental variable set here by only using levels of investment lagged two and three times as instruments in the first differenced equations, in column 6 , the Sargan test shows no sign of rejecting the validity of this instrumental variable set. Based on these instrument validity tests, and the effect of alternative assumptions on the coefficient estimates, we conclude that the investment rate should indeed be treated as an endogenous variable. 
In Table 7.2 we present a similar analysis of alternative assumptions about population growth. We assume here that per capita GDP is predetermined and investment is endogenous. When we treat population growth as predetermined or endogenous, we find similar results to those when we treat population growth as exogenous, albeit with coefficient estimates being less well determined in some cases. The main result here is that these alternative specifications give us no reason to reject the maintained assumption that population growth rates can be treated as exogenous, as in our preferred specification.

[Table 7.2 about here] 


\section{Notes}

1. For a detailed discussion of the Solow model please refer for example to Mankiw, Romer and Weil (1992) and Barro and Sala-i-Martin (1997) chapter 1.

2. See Hsiao (1986, pp 76-78). The sign of this bias can be derived unambiguously in cases where there are no $x_{i t}$ variables, or where all the variables $x_{i t}$ are strictly exogenous with respect to $\left(\eta_{i}+v_{i t}\right)$.

3. For further details see for example Hsiao (1986).

4. See Anderson and Hsiao (1982).

5. $\Delta x_{i t}$ can be used if $x_{i t}$ is strictly exogenous or predetermined with respect to $v_{i t}$. This should be replaced by $\Delta x_{i, t-1}$ if $x_{i t}$ is endogenous. The use of further lags beyond $\Delta y_{i, t-1}$ and $\Delta x_{i t}$ can be shown to be redundant, given the moment conditions $E\left(y_{i, t-s} \Delta v_{i t}\right)=0$ for $s \geq 2$ and $E\left(x_{i, t-1} \Delta v_{i t}\right)=0$ for $s \geq 1$ (or $s \geq 2$ if $x_{i t}$ is endogenous) that are exploited in the first differenced equations in the system.

6. When we estimate $(3.10)$, we allow both $y_{i, t-1}$ and $x_{i t}$ to be correlated with $\eta_{i}^{*}$, so there is no 'omitted variable bias' resulting from the omission of $w_{i}$.

7. Results for per worker values are available upon request.

8. Islam (1995) averages over 1960-65, 1965-70, ... . However, averaging over these overlapping periods did not alter our results.

9. Again, the results remain unchanged when the average rates from 1960-65, 
$1965-70, \ldots, 1985-90$ are used. Calculating the compound growth rates also did not alter the results.

10. Please refer to MRW ( $\mathrm{p}$ 418) for a discussion of including the level of human capital versus the investment in human capital in the Solow model.

11. For example, Karshenas and Stoneman (1995) find that there are often several decades between the first application of a new technology, and it achieving a 90 percent market penetration.

12. Freeman(1994) discusses some of the difficulties in measuring technological change.

13. The sample consists of :

22 Sub-Saharan African countries: Benin, Botswana, Cameroon, Central African Republic, Ghana, Kenya, Liberia, Malawi, Mali, Mauritius, Mozambique, Niger, Rwanda, Senegal, Sierra Leone, Sudan, Tanzania, Togo, Uganda, Zaire, Zambia, Zimbabwe.

63 other countries: Algeria, Egypt, South Africa, Tunisia, Canada, Costa Rica, Dominican Republic, El Salvador, Guatemala, Haiti, Honduras, Jamaica, Mexico, Nicaragua, Panama, Trinidad and Tobago, USA, Argentina, Bolivia, Brazil, Chile, Colombia, Ecuador, Paraguay, Peru, Uruguay, Venezuela, Bangladesh, Hong Kong, India, Israel, Japan, Jordan, Korea Republic, Malaysia, Myanmar, Nepal, Pakistan, Philippines, Singapore, Sri Lanka, Syria, Thailand, Austria, 
Belgium, Denmark, Finland, France, Germany, Greece, Ireland, Italy, Netherlands, Norway, Portugal, Spain, Sweden, Switzerland, Turkey, UK, Australia, New Zealand, Papua New Guinea.

14. This assumption is weaker than strict exogeneity, since it allows for feedback from earlier GDP shocks onto current population growth. We assess the sensitivity of our results to alternative assumptions about investment and population growth in appendix Tables 7.1 and 7.2 .

15. For example, with $T=4$ and $N=100$ and a true value of $\alpha=0.9$, the distribution of the first differenced GMM estimator has a mean of 0.23 (with a standard deviation of 0.83 ) in Table 2(a) of Blundell and Bond (1998).

16. When conducting a Hausman test the test statistic is $0.93 \sim \mathrm{N}(0,1)$, thus the coefficient estimates obtained from system GMM and the first differenced GMM estimation including extra instruments are not significantly different at conventional levels.

17. Using a Hausman test we find that the test statistic is $2.01 \sim \mathrm{N}(0,1)$. Thus, it rejects the extra moment conditions used by the levels estimator, compared to the system GMM estimator. In other words it rejects the null hypothesis that there are no unobserved country specific effects. Note that this is consistent with the Sargan test for the IV levels estimator.

18. Please refer to Arellano and Bond (1991). They present a discussion of 
the test statistic for serial correlation which we report in the tables, it is asymptotically normally distributed. For the OLS levels estimates the serial correlation test tests whether the level of the error terms are uncorrelated, whereas for the GMM estimates, they test whether the first differences of the error terms are uncorrelated.

19. Notice that in the IV levels results reported here, we have used a reduced number of instruments, rather than all the available lags. As discussed in the appendix Table 7.1, this increased the power of the Sargan test to detect misspecification, but had very little impact on the estimated coefficients.

20. When conducting a Hausman test the test statistic is $1.57 \sim \mathrm{N}(0,1)$, thus the coefficient estimates obtained from system GMM and IV levels estimation are not significantly different at the 10 percent level.

21. See for example Pritchett (1996).

22. One potentially important question is whether the conventionally used empirical growth models are really adequate to explain Africa's growth, or whether Africa is just too different from other regions and thus Africa specific models should be analysed. Savvides (1995), Ojo and Oshikoya (1995) as well as Hadijmichael et al. (1995) use commonly used specifications of growth models in order to examine Africa's growth performance. Rather than using a global sample they only include African countries in their studies. Their analyses show that the com- 
monly found results, for example conditional convergence and a strong positive effect of investment on growth, hold for this reduced sample. We interpret this as evidence that there is no need to concentrate on an Africa specific model.

23. These are the same estimates as in Table 3.2 , column 4 .

24. We assume that current and previous five year period shocks to GDP per capita are uncorrelated with current investment, but that shocks to GDP per capita lagged two or more periods may be correlated with current investment.

25. Similarly we use only the current and first lag of population growth, and only the second and third lags of GDP per capita - rather than all the available lags - as instruments in these reduced instrument sets. 


\section{References}

[1] Anderson T.W. and C. Hsiao, 1982, Formulation and Estimation of Dynamic Models Using Panel Data, Journal of Econometrics 18, 47-82.

[2] Arellano, M. and S. Bond, 1998, Dynamic Panel Data Estimation Using: DPD98 for GAUSS: A Guide for Users, Institute for Fiscal Studies, London, Working Paper No 88/15.

[3] Arellano, M. and S. Bond, 1991, Some Tests of Specification for Panel Data: Monte Carlo Evidence and an Application to Employment Equations, Review of Economic Studies 58, 277-97.

[4] Arellano, M. and O. Bover, 1995, Another Look at the Instrumental Variable Estimation of Error-Components Models, Journal of Econometrics 68, 29-52.

[5] Barro, R. J., 1991, Economic Growth in a Cross Section of Countries, The Quarterly Journal of Economics 106, 407-43.

[6] — 1997, Determinants of Economic Growth (MIT Press, Cambridge, MA).

[7] —, and J. W. Lee, 1996, International Measures of Schooling Years and Schooling Quality, American Economic Review, Papers and Proceedings 86, $218-23$

[8] —, and X. Sala-i-Martin, 1995, Economic Growth (McGraw-Hill, New York). 
[9] Blundell, R. and S. Bond, 1998, Initial Conditions and Moment Restrictions in Dynamic Panel Data Models, Journal of Econometrics 87, 115-43.

[10] —, and-, 1999, GMM Estimation with Persistent Panel Data: An Application to Production Functions, Institute for Fiscal Studies, London, Working Paper No 99/4.

[11] Caselli, F., G. Esquivel and F. Lefort, 1996, Reopening the Convergence Debate: A New Look at Cross-Country Growth Empirics, Journal of Economic Growth 1, 363-89.

[12] Easterly, W., and R. Levine, 1997, Africa's Growth Tragedy: Politics and Ethnic Divisions, The Quarterly Journal of Economics 112, 1203-50.

[13] —, and —, 1998, Troubles with the Neighbours: Africa's Problem, Africa's Opportunity, Journal of African Economies 7, 120-42.

[14] Freeman, C., 1994, The Economics of Technical Change, Cambridge Journal of Economics 18, 463-514.

[15] Gemmell, N., 1996, Evaluating the Impacts of Human Capital Stocks and Accumulation on Economic Growth: Some New Evidence, Oxford Bulletin of Economics and Statistics 58, 9-28. 
[16] Hadjimichael, M. T., G. Dhaneshwar, M. Mühleisen, R. Nord, and M. E. Ucer, 1995, Sub-Saharan Africa: Growth, Savings, and Investment, 1986-93, IMF Occasional Paper No 118, January 1995, Washington.

[17] Hansen, L.P., 1982, Large Sample Properties of Generalised Method of Moment Estimators, Econometrica 50, 1029-54.

[18] Hsiao, C., 1986, Analysis of Panel Data (Cambridge University Press, Cambridge, MA).

[19] Islam, N., 1995, Growth Empirics: A Panel Data Approach. The Quarterly Journal of Economics 110, 1127-70.

[20] Kershenas, M. and P. Stoneman, 1995, Technological Diffusion, in: Handbook of the Economics of Innovation and Technological Change, ed. P. Stoneman (Blackwell, Oxford) 265-97.

[21] Levine, R. and D. Renelt, 1992, A Sensitivity Analysis of Cross-Country Growth Regressions, American Economic Review 82, 942-63.

[22] Mankiw, G. N., D. Romer and D. N. Weil, 1992, A Contribution to the Empirics of Economic Growth, The Quarterly Journal of Economics 107, 407-37. 
[23] Nickell, S., 1981, Biases in Dynamic Models with Fixed Effects, Econometrica $49,1417-26$.

[24] Ojo, O. and T. Oshikoya, 1995, Determinants of Long-Term Growth: Some African Results, Journal of African Economies 4, 163-91.

[25] Pritchett, L., 1996, Where Has All the Education Gone? World Bank, Policy Research Working Paper, 1581.

[26] Romer, P. M., 1990, Human Capital and Growth: Theory and Evidence, Carnegie-Rochester Conference Series on Public Policy 32, 251-86.

[27] Sachs, J. D. and A. M. Warner, 1997, Sources of Slow Growth in African Economies, Journal of African Economies 6, 335-76.

[28] Sala-i-Martin, X., 1997a, I Just Ran Four Million Regressions, Columbia University, mimeo.

[29] —, 1997b, I Just Ran Two Million Regressions, American Economic Review $87,178-83$.

[30] Savvides, A. 1995. Economic Growth in Africa. World Development 23, 44958. 


\section{Tables}

Table 4.1: Textbook Solow Model

\begin{tabular}{lllllll}
\hline & $(1)$ & $(2)$ & $(3)$ & $(4)$ & $(5)$ & $(6)$ \\
& OLS & WG & $\begin{array}{l}\text { DIF- } \\
\text { GMM }\end{array}$ & $\begin{array}{l}\text { SYS- } \\
\text { GMM }\end{array}$ & $\begin{array}{l}\text { DIF-GMM } \\
\text { extra instr. }\end{array}$ & $\begin{array}{l}\text { IV } \\
\text { Levels }\end{array}$ \\
\hline $\ln \left(\mathrm{y}_{t-1}\right)$ & -0.035 & -0.227 & -0.222 & -0.100 & -0.148 & -0.022 \\
& $(0.012)$ & $(0.046)$ & $(0.082)$ & $(0.041)$ & $(0.066)$ & $(0.013)$ \\
$\ln ($ investm. $)$ & 0.102 & 0.159 & 0.100 & 0.208 & 0.157 & 0.077 \\
& $(0.014)$ & $(0.028)$ & $(0.057)$ & $(0.041)$ & $(0.049)$ & $(0.017)$ \\
$\ln (\mathrm{n}+\mathrm{g}+\delta)$ & -0.190 & -0.381 & -0.322 & -0.428 & -0.350 & -0.178 \\
& $(0.069)$ & $(0.119)$ & $(0.141)$ & $(0.168)$ & $(0.134)$ & $(0.072)$ \\
\hline$\lambda$ & 0.007 & 0.051 & 0.050 & 0.021 & 0.032 & 0.004 \\
& $(0.002)$ & $(0.012)$ & $(0.012)$ & $(0.007)$ & $(0.011)$ & $(0.003)$ \\
$\mathrm{m}_{1}$ & 3.48 & -4.34 & -3.55 & -4.36 & -3.92 & 3.34 \\
$\mathrm{~m}_{2}$ & 1.46 & 0.20 & 0.08 & -0.05 & -0.01 & 1.40 \\
SarganTest & & & 0.04 & 0.21 & 0.12 & 0.06 \\
Diff. Sargan & & & & 0.99 & 0.82 & \\
\hline
\end{tabular}

Note: Standard errors in parentheses. The test statistics for first and second order correlation are given by $m_{1}$ and $m_{2}$, respectively (distributed as standard normals). The figures reported for the Sargan tests are the p-values of the null hypothesis, valid specification. 
Table 4.2: Augmented Solow Model

\begin{tabular}{llllll}
\hline & $(1)$ & $(2)$ & $(3)$ & $(4)$ & $(5)$ \\
& OLS & WG & DIF-GMM & SYS-GMM & IV Levels \\
\hline $\ln \left(\mathrm{GDP}_{t-1}\right)$ & -0.047 & -0.229 & -0.175 & -0.118 & -0.040 \\
& $(0.014)$ & $(0.046)$ & $(0.071)$ & $(0.052)$ & $(0.015)$ \\
$\ln ($ investm. $)$ & 0.095 & 0.160 & 0.152 & 0.217 & 0.066 \\
& $(0.013)$ & $(0.028)$ & $(0.051)$ & $(0.039)$ & $(0.017)$ \\
$\ln (\mathrm{n}+\mathrm{g}+\delta)$ & -0.197 & -0.367 & -0.314 & -0.439 & -0.188 \\
& $(0.068)$ & $(0.128)$ & $(0.146)$ & $(0.163)$ & $(0.071)$ \\
$\ln ($ schooling $)$ & 0.022 & -0.017 & -0.034 & 0.005 & 0.032 \\
& $(0.013)$ & $(0.037)$ & $(0.046)$ & $(0.035)$ & $(0.013)$ \\
\hline$\psi$ & 0.010 & 0.052 & 0.038 & 0.025 & 0.008 \\
& $(0.003)$ & $(0.007)$ & $(0.012)$ & $(0.009)$ & 0.003 \\
$m_{1}$ & 3.53 & -7.19 & -3.79 & -4.40 & 3.46 \\
$m_{2}$ & 1.43 & 0.30 & 0.02 & -0.02 & 1.39 \\
SarganTest & & & 0.12 & 0.40 & 0.04 \\
Diff. Sargan & & & & 0.98 & \\
\hline
\end{tabular}

Note: Standard errors in parentheses. The test statistics for first and second order correlation are given by $m_{1}$ and $m_{2}$, respectively (distributed as standard normals). The figures reported for the Sargan tests are the p-values of the null hypothesis, valid specification. 
Table 5.1: Descriptive Statistics

\begin{tabular}{lllll}
\hline & Sample & OECD & $\begin{array}{l}\text { non- } \\
\text { OECD }\end{array}$ & SSA \\
\hline per capita GDP growth* & 1.89 & 2.93 & 1.52 & 0.52 \\
real GDP per capita (US $\$)^{* *}$ & 2250 & 5592 & 1487 & 835 \\
investment to GDP ratio $^{*}$ & 16.29 & 25.87 & 12.95 & 9.04 \\
population growth* & 1.66 & 0.61 & 2.03 & 2.21 \\
initial total years of schooling** $^{*}$ & 3.47 & 6.56 & 2.39 & 1.27 \\
\hline number of countries & 85 & 22 & 63 & 22 \\
\hline
\end{tabular}

Notes: ${ }^{*}$ indicates annual averages given in percent, ${ }^{* *}$ measured for the earliest available year, for most countries in 1960 
Table 5.2: Africa's Low Growth Performance

\begin{tabular}{llll}
\hline & $(1)$ & $(2)$ & $(3)$ \\
& OLS & SYS-GMM & Step 2 \\
\hline $\ln y_{t-1}$ & -0.057 & -0.118 & \\
& $(0.013)$ & $(0.052)$ & \\
$\ln ($ inv $)$ & 0.090 & 0.217 & \\
& $(0.015)$ & $(0.039)$ & \\
$\ln (n+g+\delta)$ & -0.207 & -0.439 & \\
& $(0.066)$ & $(0.163)$ & \\
$\ln ($ schooling $)$ & 0.019 & 0.005 & \\
& $(0.012)$ & $(0.035)$ & \\
$S S A$ & -0.050 & & -0.017 \\
& $(0.025)$ & & $(0.031)$ \\
\hline $\mathrm{m}_{1}$ & 4.76 & -4.40 & 4.50 \\
$\mathrm{~m}_{2}$ & 2.02 & -0.02 & 3.45 \\
\hline
\end{tabular}

Note: Standard errors in parentheses. $n=489$, 85 countries 
Table 7.1: Investment and Growth

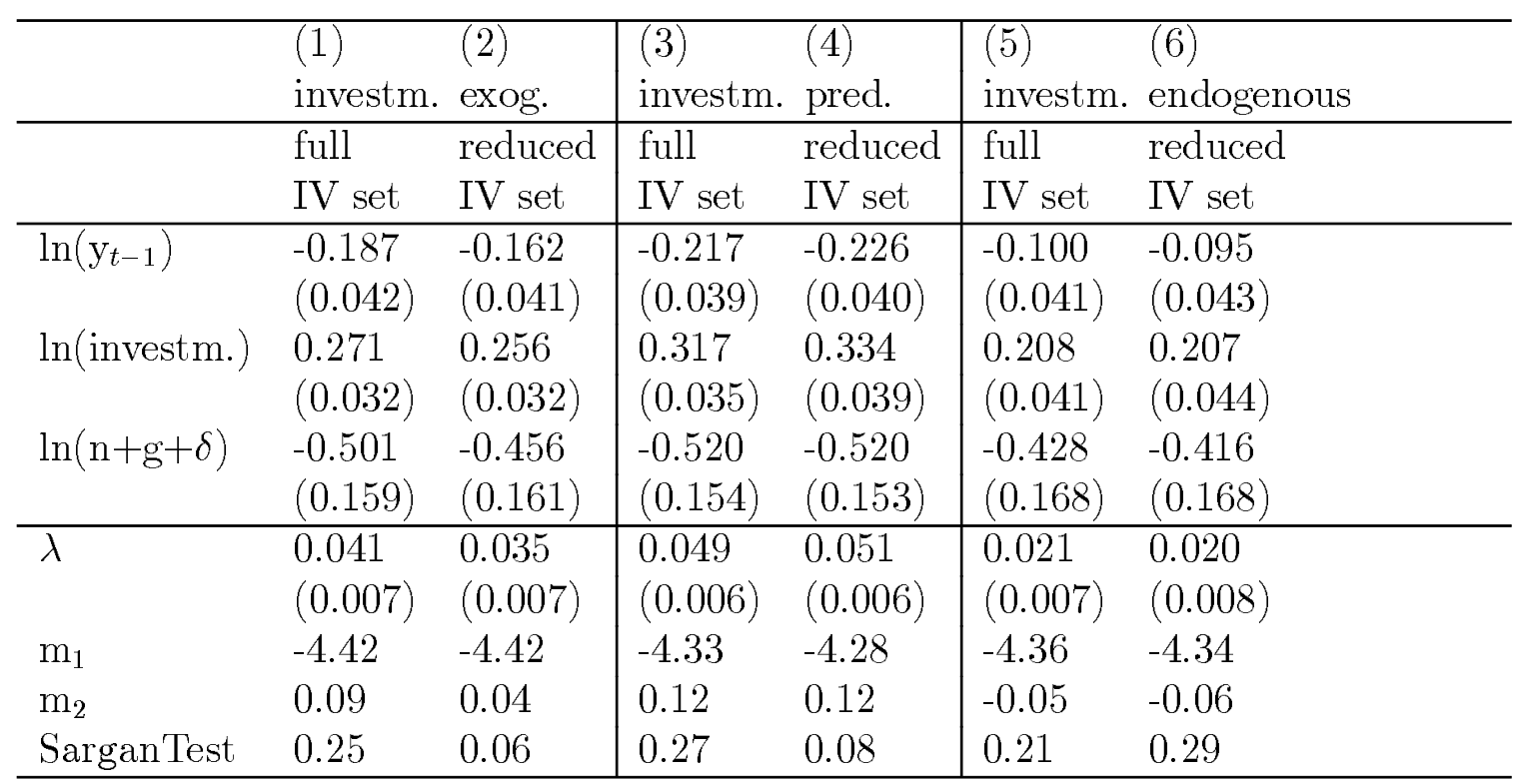

Note: Standard errors in parentheses. The test statistics for first and second order correlation are given by $m_{1}$ and $m_{2}$, respectively (distributed as standard normals). The figures reported for the Sargan tests are the p-values of the null hypothesis, valid specification. We treat $\ln \left(y_{t-1}\right)$ as predetermined and $\ln (n+g+\delta)$ as exogenous. 
Table 7.2: Population Growth

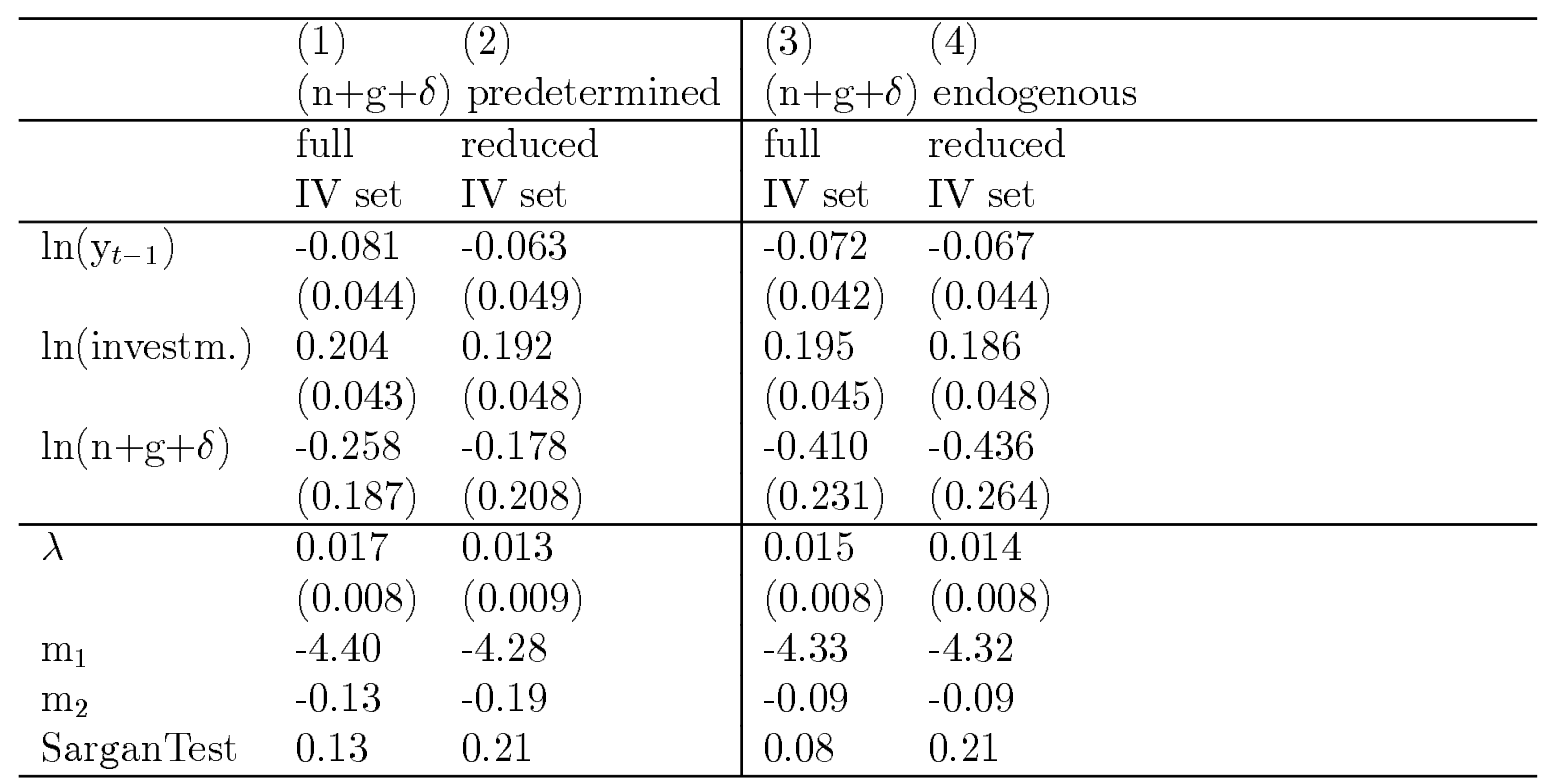

Note: Standard errors in parentheses. The test statistics for first and second order correlation are given by $m_{1}$ and $m_{2}$, respectively (distributed as standard normals). The figures reported for the Sargan tests are the p-values of the null hypothesis, valid specification. We treat $\ln \left(y_{t-1}\right)$ as predetermined and $\ln$ (investm.) as endogenous. 